\title{
Phosphorus acquisition of wheat, pea and narrow-leafed lupin under different $P$ supplies
}

\author{
P. Sandaña ${ }^{1,3^{*}} \&$ D. Pinochet ${ }^{2}$
}

${ }^{1}$ Graduate School, Faculty of Agricultural Sciences, Campus Isla Teja, Universidad Austral de Chile. Valdivia, Chile. ${ }^{2}$ Institute of Agricultural Engineering and Soil Science, Campus Isla Teja, Universidad Austral de Chile. Valdivia, Chile. ${ }^{3}$ Instituto de Investigaciones Agropecuarias (INIA-Remehue), Ruta 5 Sur km 8 Norte, Osorno Chile. *Corresponding author: patricio.sandana@inia.cl

\begin{abstract}
The aim of this study was to compare wheat, pea and narrow-leafed lupin in terms of their ability to acquire $\mathrm{P}$ from soil. Two experiments were conducted at the Universidad Austral de Chile. Treatments combined (i) three species (wheat, pea and lupin) and (ii) two rates of P fertilization ( 0 (P0) and $50 \mathrm{mg} \mathrm{P} \mathrm{kg}^{-1}$ (P1)). In Experiment 1 and 2 , shoot biomass was affected $(\mathrm{P}<0.01)$ by genotype, $\mathrm{P}$ rate and the genotype $\mathrm{x} \mathrm{P}$ rate interaction. In wheat, pea and lupin P0 reduced this trait by 92, 76 and 41\%, respectively, whereas in Experiment 2 these reductions were 86,58 and 44\%, respectively. P1 increased the P uptake of wheat, pea and lupin by 17, 5 and 3 times, respectively. Wheat, pea and lupin showed the highest, intermediate and lowest cumulative root length under $\mathrm{P}$ fertilization. The root: shoot ratio and $\mathrm{P}$ uptake per unit root length was affected by genotype, $\mathrm{P}$ rate and the genotype $x$ P rate interaction. Wheat, pea and lupin showed the highest, intermediate and the lowest root: shoot ratio, respectively. In contrast, wheat and lupin showed the lowest and the highest $\mathrm{P}$ uptake per unit root length in both experiments. The present study showed consistent differences between wheat, pea and lupin regarding their sensitivity to P deficiency and the strategies that these species have developed to acquire P from soil. This information could help improve fertilizer management strategies and optimize soil P use.
\end{abstract}

Keywords: Wheat, pea, lupin, phosphorus, roots

\section{Introduction}

Although soils have a large amount of phosphorus (P), most $\mathrm{P}$ is non-labile and is tightly fixed to mineral or organic compounds, rendering it unavailable to many plants (Watt and Evans, 2003; Balemi and Negisho, 2012; Manschadi et al., 2014). As a result, a large number of phosphate fertilizers have been applied in agricultural systems since the green revolution.
However, there are some trends likely to drive the effort to improve P use efficiency (PUE) of crop production systems, since phosphate rock could be depleted in the next 50 to 100 years (Cordell et al., 2009). In addition, improvements in PUE are in line with the current challenge to produce higher yields with inputs that do not cause environmental 
problems on or off-site (Gregory and George, 2011). PUE (kg biomass $\mathrm{kg}^{-1} \mathrm{P}$ available (P from soil plus fertilizer)) for biomass production can be defined as the product of $\mathrm{P}$ uptake efficiency ( $\mathrm{kg} \mathrm{P}$ uptake $\mathrm{kg}^{-1}$ $\mathrm{P}$ available) and $\mathrm{P}$ utilization efficiency ( $\mathrm{kg}$ biomass $\mathrm{kg}^{-1} \mathrm{P}$ uptake) (Ortiz-Monasterio et al., 2001; Sandaña and Pinochet, 2014; Sandaña, 2016). Despite the global need to improve the PUE of crops, the degree of knowledge reached among crop species regarding their PUE is unequal. There are many studies in cereals with regard to their abilities to acquire P (Ortiz-Monasterio et al., 2001; Bayuelo-Jiménes and Ochoa-Cadavid, 2014); however, much less information is available in temperate grain legumes such as pea (Pisum sativum L.) and narrow-leafed lupin (Lupinus angustifolius L.). Studies comparing yield or biomass responses of cereals and legumes under different $\mathrm{P}$ fertilization are available (Bolland et al., 1999), yet there is a paucity of studies assessing PUE and related root traits. In southern Chile $\left(40^{\circ} \mathrm{S}, 70^{\circ} \mathrm{W}\right)$, wheat is the most frequently sown grain crop, and pea and narrow-leafed lupin are alternative crops for plant protein production. Recently, Sandaña and Pinochet (2014) showed that $\mathrm{P}$ uptake efficiency of wheat and pea under P deficiency was slightly different for these crops (1.01 and $1.16 \mathrm{~g} \mathrm{P} \mathrm{g}^{-1} \mathrm{P}$ available, respectively), with these crops presenting different strategies for $\mathrm{P}$ acquisition. Wheat had a higher soil exploratory capacity than pea. Considering that legume species are being incorporated more and more into cropping systems as a way of improving the sustainability of cereal production (Giunta et al., 2009), it is important to compare the abilities of these species (including narrow-leafed lupin) to acquire $\mathrm{P}$ in soils with high $\mathrm{P}$ - fixing capacities such as the andisols in southern Chile (Valle et al., 2015).

A variety of root traits such as root size, morphology, root diameter, root hairs and root-induced processes in the rhizosphere are involved in the variation of $\mathrm{P}$ uptake rates among crop species and their genotypes (Jungk, 2002; Gahoonia and Nielsen, 2004; Wang et al., 2010). The strategies plants have developed for high uptake efficiency differ among species. Some produce large root systems while others have a high uptake per unit of root length (Föhse et al., 1988). Föhse et al. (1988) reported that the ability of root systems to acquire $\mathrm{P}$ from soil depends on the ability of roots to absorb $\mathrm{P}$ per unit of root length, the active life-time of roots and the amount of root per unit of shoot. Larger roots provide greater root-soil contact, which is particularly important in nutrients with lower mobility such as P. In general, temperate cereals such as wheat and barley have shown greater root length and specific root length than legumes under different water regimes (Gregory, 1994; Gregory and Eastham, 1996). However, there have been no studies comparing root growth and uptake per unit of root length of wheat, pea and narrow-leafed lupin to acquire $\mathrm{P}$, which would elucidate possible differences among these species on this issue.

Therefore, the aim of this study was to compare the root properties of wheat, pea and narrow-leafed lupin in relation to their P uptake efficiencies.

\section{Materials and Methods}

\subsection{Treatments and design}

Two pot experiments were conducted at the Universidad Austral de Chile, Valdivia (39 $47^{\circ}$ 'S, $73^{\circ} 14^{\prime}$ W, $19 \mathrm{~m}$ a.s.1.), Chile. In each experiment, treatments combined (i) three species and (ii) two $\mathrm{P}$ fertilization rates $\left(0(\mathrm{P} 0)\right.$ and $\left.50 \mathrm{mg} \mathrm{P} \mathrm{kg}^{-1}(\mathrm{P} 1)\right)$. The species were spring wheat (cv. Pandora), pea (semi-leafless cv. Nitouche) and narrow-leafed lupin (cv. Belara). In both experiments treatments, with three replicates, were arranged in a completely randomized design. In 
both experiments the soil was obtained from a field site located at the Universidad Austral de Chile's experimental station. The soil series was Valdivia (textural class: silty loam) characterized by 8,68 and $24 \%$ of sand, silt and clay, respectively. Initially, the soil had a $\mathrm{pH}$ of 5.8 (water $(1: 2.5)), 13.5 \%$ organic matter, $13.3 \mathrm{mg} \mathrm{N} \mathrm{kg}^{-1}\left(\mathrm{NO}_{3}+\mathrm{NH}_{4}\right)$, and $8.7 \mathrm{mg} \mathrm{kg}^{-1}$ Olsen P. Exchangeable cations $\left(\mathrm{cmol}+\mathrm{kg}^{-1}\right)$ were $4.39,0.47,0.60,0.09$ and 0.15 for $\mathrm{Ca}, \mathrm{Mg}, \mathrm{K}, \mathrm{Na}$ and $\mathrm{Al}$, respectively.

\subsection{Management}

Plants were grown in glass-walled boxes, similar to those used by Liao et al. (2006). Boxes constructed from stainless steel were $0.25 \mathrm{~m}$ long, $0.15 \mathrm{~m}$ wide and $1.0 \mathrm{~m}$ deep, with one glass side to map root growth. The glass side was covered with a black polyethylene sheet to avoid any root exposure to light. The boxes were placed on steel stands at an angle of $60^{\circ}$ from the soil and spaced $0.1 \mathrm{~m}$ apart. The boxes were filled with soil to a depth of $1.0 \mathrm{~m}$. The soil was put through a $2 \mathrm{~mm}$ sieve and then packed to a bulk density of approximately $0.70 \mathrm{~g} \mathrm{~cm}^{-}$ ${ }^{3}$. $\mathrm{N}$ and $\mathrm{K}$ were incorporated up to a depth of 0.2 $\mathrm{m}$ at rates of $0.5 \mathrm{~g}$ as urea $(46 \% \mathrm{~N})$ and muriate of potash $(55 \% \mathrm{KCl})$, respectively. In $\mathrm{P} 1$ treatments, 50 mg kg-1 of P was homogeneously incorporated into the soil to a depth of $20 \mathrm{~cm}$. Five days after germination, 10 plants were carefully transplanted into rows next to the glass walls in each box on March 11 and September 22, in Experiments 1 and 2, respectively. The plants were grown outdoors in Experiment 1 and in a greenhouse in Experiment 2. Both experiments were exposed to natural light and temperatures. The plants were surface-irrigated daily by hand to avoid water shortages until harvest. Weeds were removed by hand, while diseases and insects were prevented with the use of fungicides and insecticides.

\subsection{Measurements}

Similar to Liao et al. (2006), the root growth was observed twice weekly. For each observation, the black polyethylene sheet was removed and replaced with a transparent polyethylene sheet film. The visible new roots were traced on the transparent sheet using a waterproof permanent pen. Afterwards, the visible new roots were also marked on the glass wall. Thus, it was possible to easily identify the new root growth in the next measurement. The glass wall was then covered with the black cover-sheet until the next measurement. The root growth was followed until most roots reached the bottom of the boxes. Each transparent film for each mapping day was cut into five 0.2 $\mathrm{m}$ sections and each section was scanned (Canoscan Lide 20, Canon scanner). The images were analyzed for root length in each section and for each mapping day using the computer software WinRhizo. Considering that not all the roots grown in the root box were displayed on the glass wall, these measurements were considered an indicator of root growth.

Plants were harvested on May 10 and November 11 in Experiments 1 and 2 respectively, by cutting the shoots from the roots at the crown. Roots were harvested in five sections of $0.2 \mathrm{~m}$. Most of the roots were carefully recovered from the soil by repeated sieving with a $2 \mathrm{~mm}$ sieve to produce a clean sample. Then, roots were washed by hand. The root length from each soil layer was measured using the WinRhizo software. Previouly, this software was calibrated with Tennant's line intersection method (Tennant, 1975) using a scanner image. Shoot and root samples were then weighed in an electronic balance (Mettler Toledo XP205DR, Greifensee, Switzerland) after oven drying for $48 \mathrm{~h}$ at $65^{\circ} \mathrm{C}$. Afterward, the $\mathrm{P}$ concentration in the shoot biomass samples was measured with the phospho-vanademolybdate yellow method. 


\subsection{Statistical analysis}

The treatment effects on variables were evaluated using an analysis of variance. Means were compared using the Tukey test $(\mathrm{P}=0.05)$ in each experiment. Relationships between variables were determined through linear regression analyses and the regression coefficients were compared with the Student's t-test.
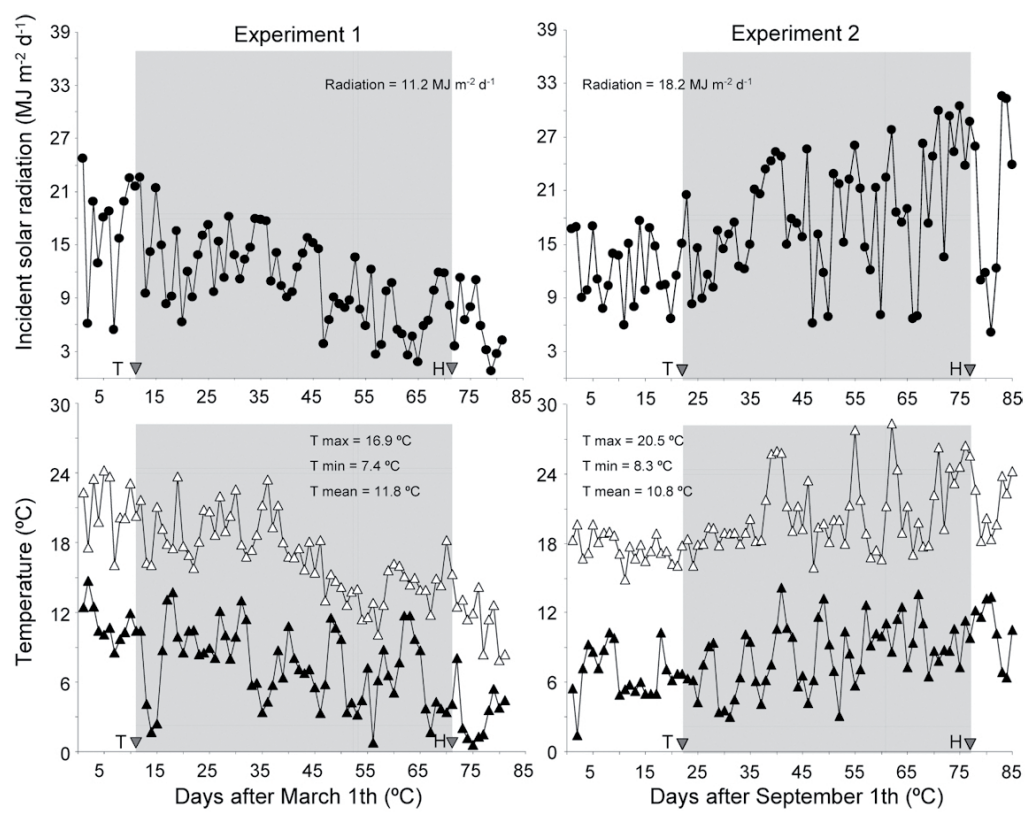

Figure 1. Daily incident solar radiation (upper panels) and daily maximum and minimum temperatures (lower panels) during Experiments 1 and 2. $\mathrm{T}$ and $\mathrm{H}$ indicate the moment of transplant and harvest, respectively. Averaged values of radiation and temperatures during each experiment are presented inside each figure.

\section{Results}

The climatic conditions of both pot experiments are presented in Figure 1. Plants were exposed to different environments. In Experiment 1, both climatic variables decreased during the evaluation period. The average incident solar radiation was $11.2 \mathrm{MJ} \mathrm{m}^{-2} \mathrm{~d}^{-1}$, while the average maximum, minimum and mean temperatures were $16.9,7.4$ and $11.8{ }^{\circ} \mathrm{C}$, respectively. In contrast, climatic variables increased throughout Experiment 2. The average incident solar radiation was higher than in Experiment 1, being 18.2 $\mathrm{MJ} \mathrm{m}^{-2} \mathrm{~d}^{-1}$, while the average maximum, minimum and mean temperatures were $20.5,8.3$ and $10.8{ }^{\circ} \mathrm{C}$, respectively.

In Experiments 1 and 2, shoot biomass was affected ( $\mathrm{P}$ $<0.01$ ) by genotype, $\mathrm{P}$ rate and the genotype $\mathrm{x} P$ rate interaction (Table 1). Averaged across experiments, under treatment P1, wheat, pea and narrow-leafed lupin reached a shoot biomass of 1.54, 0.82 and 0.83 g plant ${ }^{-1}$. Consistently, genotypes showed different sensitivities (significant interaction), with wheat being the most sensitive, pea intermediate and narrowleafed lupin the most tolerant to $\mathrm{P}$ deficiency (P0); in Experiment 1, shoot biomass of wheat, pea and 
narrow-leafed lupin decreased by 92,76 and $41 \%$, respectively, while in Experiment 2 these reductions were 86,58 and $44 \%$ (Table 1).
In both experiments the $\mathrm{P}$ concentration was affected ( $\mathrm{P}$ $<0.01$ ) by genotypes and the $P$ rate, and in experiment 1 by genotype $\mathrm{x} P$ rate interaction (Table 1 ).
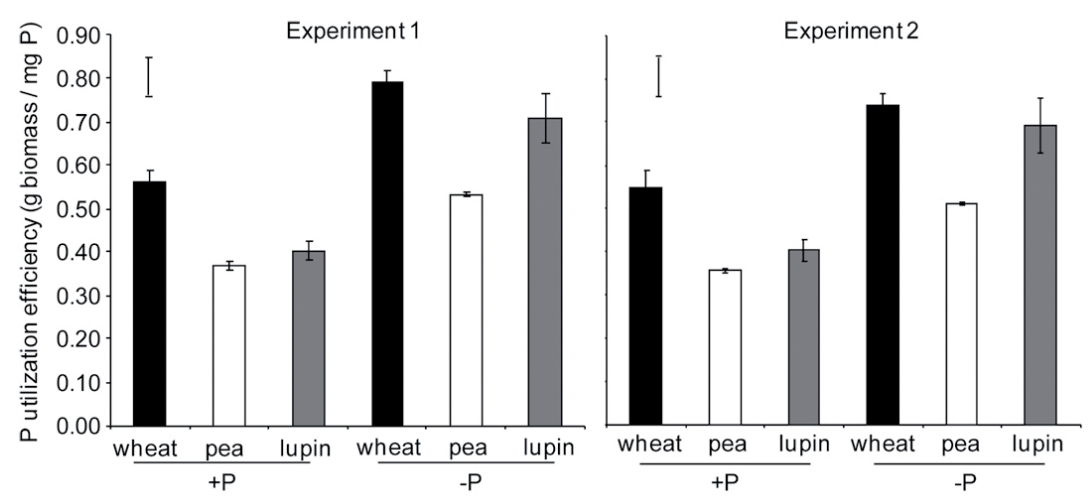

Figure 2. Phosphorus utilization efficiency ( $\mathrm{g}$ biomass $\mathrm{mg}^{-1} \mathrm{P}$ uptake) of wheat (black bars), pea (white bars) and lupin (grey bars) under treatments with $(+\mathrm{P})$ and without $\mathrm{P}(-\mathrm{P})$ fertilization in Experiments 1 and 2 . The vertical bars which appear in the bars represent the standard error of the mean. The vertical bars which appear alone represent Tukey test at $\mathrm{P}=0.05$.

Across experiments, $\mathrm{P}$ concentration of wheat, pea and narrow-leafed lupin ranged between $0.13-0.18$, $0.19-0.28$ and $0.14-0.25 \%$, respectively. P1 increased the $\mathrm{P}$ concentration in wheat, pea and narrow-leafed lupin on average by 34,41 and $73 \%$, respectively. In agreement with the $\mathrm{P}$ concentration, the $\mathrm{P}$ utilization efficiency ( $\mathrm{g}$ biomass $\mathrm{mg}^{-1} \mathrm{P}$ uptake) was affected ( $\mathrm{P}$ $<0.01$ ) by genotypes and $\mathrm{P}$ rate in both experiments (Figure 2). On average, wheat and pea showed the highest and the lowest P utilization efficiency (Figure 2). In both experiments this trait was decreased by $\mathrm{P} 1$ on average by 27,30 , and $42 \%$ in wheat, pea and narrow-leafed lupin, respectively. In addition, $\mathrm{P}$ uptake was affected $(\mathrm{P}<0.01)$ in both experiments by genotypes, $\mathrm{P}$ rate and genotype $\mathrm{x} \mathrm{P}$ rate interaction. Wheat and narrow-leafed lupin showed contrasting sensitivities to $\mathrm{P}$ fertilization regarding $\mathrm{P}$ uptake, since on average, $\mathrm{P}$ fertilization increased the $\mathrm{P}$ uptake of wheat, pea and narrow-leafed lupin 17, 5 and 3 times, respectively (Table 1).

Root biomass was affected by genotypes only in Experiment 1 , whereas in both experiments this trait was affected by the $\mathrm{P}$ rate and genotype $\mathrm{x} P$ rate interaction. In Experiment 1, on average, narrow-leafed lupin showed 31 and 51\% higher root biomass than wheat and pea, respectively. Across experiments the $\mathrm{P}$ deficiency reduced the root biomass of wheat, pea and narrow-leafed lupin by 78, 40 and 33\%, respectively. Root length was affected $(\mathrm{P}<0.01)$ in both experiments by genotypes, $P$ rate and genotype $x$ P rate interaction. Wheat showed the highest root length followed by pea and narrow-leafed lupin, respectively. 
On average, $\mathrm{P}$ deficiency decreased the root length of wheat, pea and narrow-leafed lupin by 80,41 and $36 \%$, respectively (Table 1 ). On the other hand, in both experiments the root: shoot ratio was affected $(\mathrm{P}<0.01)$ by genotypes, the $\mathrm{P}$ rate and the genotype $\mathrm{x} P$ rate interaction (Table 1). Across experiments, wheat, pea and narrow-leafed lupin showed the highest, intermediate and lowest root:shoot ratio $\left(\mathrm{cm} \mathrm{mg}^{-1}\right)$, respectively. $\mathrm{P}$ fertilization reduced the root:shoot ratio, but to differing extents depending on the genotype species; on average, $P$ fertilization reduced this trait by 44,43 and $9 \%$ in wheat, pea and narrow-leafed lupin, respectively (significant genotype $\mathrm{x}$ P rate interaction) (Table 1).

Table 1. Shoot biomass (SB), root: shoot ratio (R/S), P concentration in shoots (P \%), P uptake (PU), total root length (RL), P uptake per unit of root length (PURL) of wheat, pea and narrow-leafed lupin in Experiments 1 and 2.

\begin{tabular}{|c|c|c|c|c|c|c|c|c|}
\hline Exp. & Crops & P levels & $\begin{array}{c}\text { SB } \\
\left(\text { g plant }^{-1}\right)\end{array}$ & $\mathrm{R} / \mathrm{S}\left(\mathrm{cm} \mathrm{mg}^{-1}\right)$ & $\begin{array}{c}P \\
(\%)\end{array}$ & $\begin{array}{c}\text { PU } \\
\left(\mathrm{mg} \mathrm{plant}^{-1}\right)\end{array}$ & $\begin{array}{l}\mathrm{RL} \\
(\mathrm{m})\end{array}$ & $\begin{array}{c}\text { PURL } \\
\left(\mathrm{mg} \mathrm{P} \mathrm{m}^{-1}\right)\end{array}$ \\
\hline \multirow[t]{11}{*}{1} & \multirow[t]{2}{*}{ Wheat } & P0 & 0.13 & 8.22 & 0.13 & 0.17 & 10.4 & 0.02 \\
\hline & & P1 & 1.69 & 3.38 & 0.18 & 3.01 & 56.0 & 0.05 \\
\hline & \multirow[t]{2}{*}{ Pea } & P0 & 0.17 & 4.82 & 0.19 & 0.32 & 8.1 & 0.04 \\
\hline & & P1 & 0.70 & 2.36 & 0.27 & 1.89 & 16.4 & 0.12 \\
\hline & \multirow{7}{*}{ Lupin } & $\mathrm{P} 0$ & 0.61 & 0.53 & 0.14 & 0.87 & 3.2 & 0.28 \\
\hline & & $\mathrm{P} 1$ & 1.04 & 0.57 & 0.25 & 2.56 & 5.9 & 0.44 \\
\hline & & s.e.m & 0.018 & 0.51 & 0.01 & 0.11 & 1.12 & 0.01 \\
\hline & & Tukey value* & 0.38 & 2.52 & 0.05 & 0.56 & 5.53 & 0.07 \\
\hline & & Crop (C) & $* *$ & $* *$ & $* *$ & $* *$ & $* *$ & $* *$ \\
\hline & & P level (P) & $* *$ & $* *$ & $* *$ & $* *$ & $* *$ & $* *$ \\
\hline & & $\mathrm{C} \times \mathrm{P}$ & $* *$ & $* *$ & $*$ & $* *$ & $* *$ & $* *$ \\
\hline \multirow[t]{11}{*}{2} & \multirow[t]{2}{*}{ Wheat } & P0 & 0.20 & 2.83 & 0.14 & 0.3 & 5.6 & 0.05 \\
\hline & & P1 & 1.38 & 1.96 & 0.18 & 2.5 & 27.0 & 0.09 \\
\hline & \multirow[t]{2}{*}{ Pea } & P0 & 0.39 & 1.48 & 0.20 & 0.8 & 5.8 & 0.13 \\
\hline & & P1 & 0.93 & 0.93 & 0.28 & 2.6 & 8.6 & 0.31 \\
\hline & \multirow[t]{7}{*}{ Lupin } & P0 & 0.34 & 0.52 & 0.15 & 0.5 & 1.8 & 0.30 \\
\hline & & P1 & 0.61 & 0.39 & 0.25 & 1.5 & 2.4 & 0.66 \\
\hline & & s.e.m & 0.05 & 0.08 & 0.01 & 0.14 & 0.75 & 0.05 \\
\hline & & Tukey value* & 0.24 & 0.39 & 0.05 & 0.69 & 3.68 & 0.23 \\
\hline & & $\mathrm{C}$ & $* *$ & $* *$ & $* *$ & $* *$ & $* *$ & $* *$ \\
\hline & & $P$ & $* *$ & $* *$ & $* *$ & $* *$ & $* *$ & $* *$ \\
\hline & & $\mathrm{C} \times \mathrm{P}$ & $* *$ & $* *$ & n.s. & $* *$ & $* *$ & $*$ \\
\hline
\end{tabular}

s.e.m.: standard error of the means; n.s.: not significant; $* \mathrm{P}<0.05 ; * * \mathrm{P}<0.01$.

* Tukey value $=(4.91$ (critical value of q $(q 0.05,10,6))$ x s.e.m. $)$. Differences between treatments $\geq$ than Tukey value are significantly different at $\mathrm{P}=0.05$. 


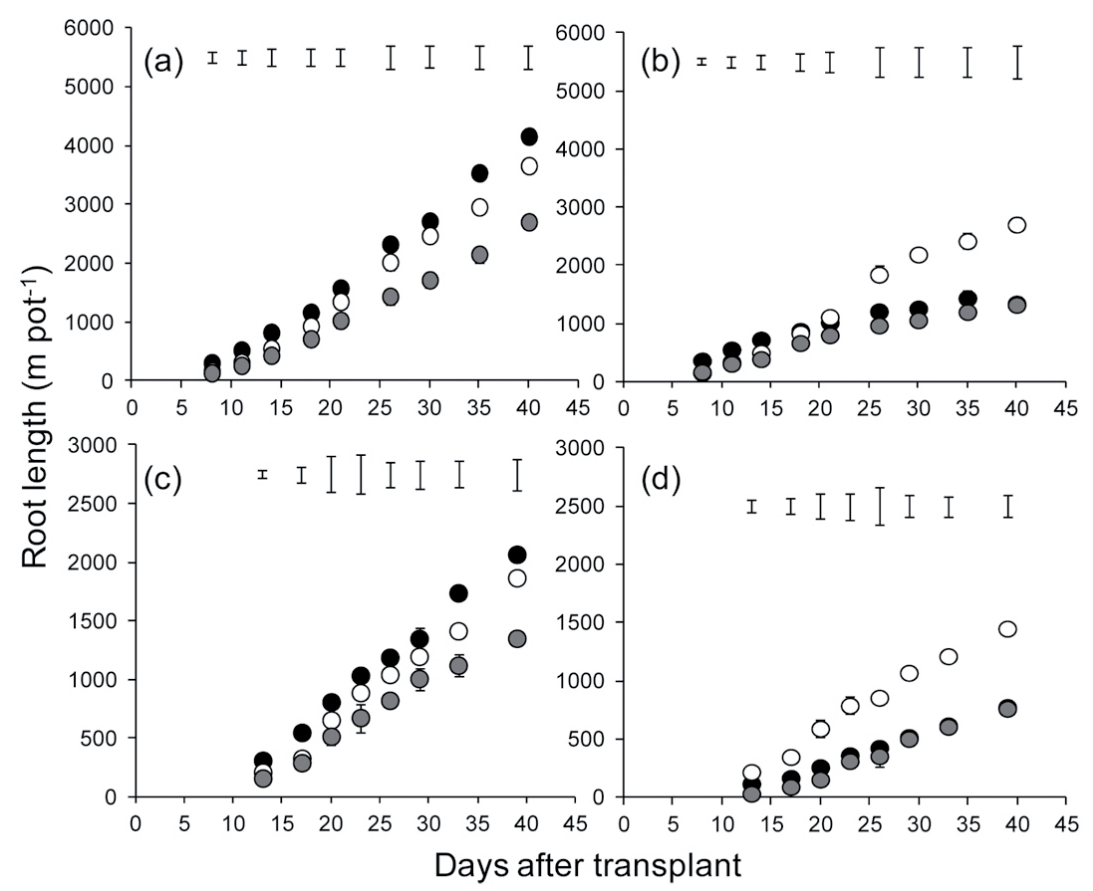

Figure 3. Accumulated total root length on the glass face of boxes of wheat (closed circles), pea (open circles) and lupin (grey circles) under treatment P1 (a and c) and P0 (b and d) in experiment 1 (a and b) and 2 (c and d). The vertical bars which appear alone represent Tukey test at $\mathrm{P}=0.05$.

In both experiments, during the assessment of root development through the glass wall, genotypes showed different $(\mathrm{P}<0.05)$ root growth. It was observed that wheat, pea and narrow-leafed lupin showed the highest, intermediate and lowest cumulative root length under P fertilization (Figure 3), as was also shown at harvest time (Table 1). However, under P deficiency, root growth was much less reduced in pea than in wheat and narrow-leafed lupin. In the last five measurements the relative reduction in root length of wheat, pea and narrow-leafed lupin was 52, 16 and 37\%, respectively in Experiment 1, whereas in Experiment 2 these reductions were 63,15 and $50 \%$, respectively (Figure 3 ).
In addition, in both experiments the root biomass of the wheat was much more reduced $(\mathrm{P}<0.05)$ by $\mathrm{P}$ deficiency than grain legumes when this trait was evaluated at different soil layer depths (Figure 4). Interestingly, wheat, pea and narrow-leafed lupin showed contrasting specific root length.

There was no clear pattern between this trait and soil layer depth (Figure 5). Averaged across experiments, the specific root length of wheat, pea and narrowleafed lupin was 74, 30 and $9 \mathrm{~m} \mathrm{~g} \mathrm{~g}^{-1}$ under $\mathrm{P}$ fertilization, while under $\mathrm{P}$ deficiency these values were similar at 64,29 and $8 \mathrm{~m} \mathrm{~g}^{-1}$, respectively. 


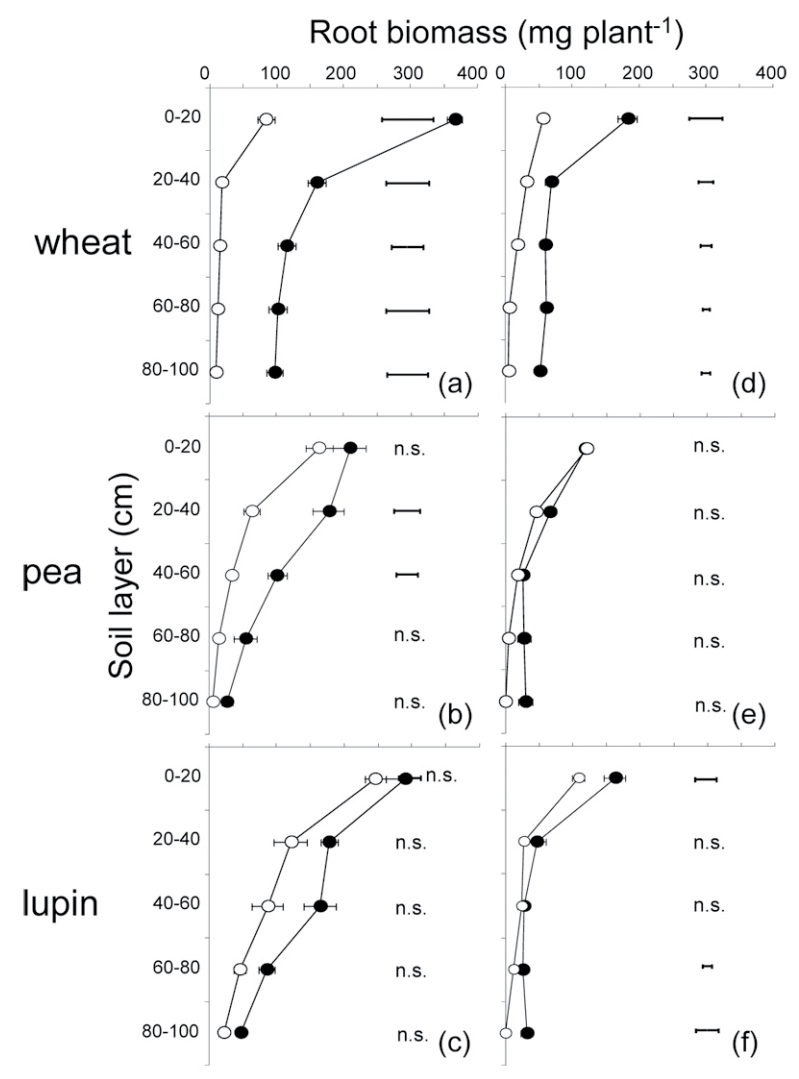

Figure 4. Root biomass of wheat, pea and lupin at different soil layers in treatment P1 (closed circles) and P0 (open circles) in Experiments $1(\mathrm{a}, \mathrm{b}, \mathrm{c})$ and 2 (d, e, f). The horizontal which appear alone represent Tukey test at $\mathrm{P}=0.05$.

The P uptake per unit root length was affected by genotypes, $\mathrm{P}$ rate and genotype $\mathrm{x} \mathrm{P}$ rate interaction (not shown). On average, in Experiment 1 wheat, pea and narrow-leafed lupin showed a $\mathrm{P}$ uptake per unit root length of $0.04,0.08$ and $0.36 \mathrm{mg} \mathrm{P} \mathrm{m}^{-1}$, while in
Experiment 2 these values were 0.07, 0.22 and 0.48 $\mathrm{mg} \mathrm{P} \mathrm{m}{ }^{-1}$, respectively (Figure 6). On average, $\mathrm{P}$ fertilization increased this trait by 115,170 and $89 \%$, in wheat, pea and narrow-leafed lupin, respectively. 


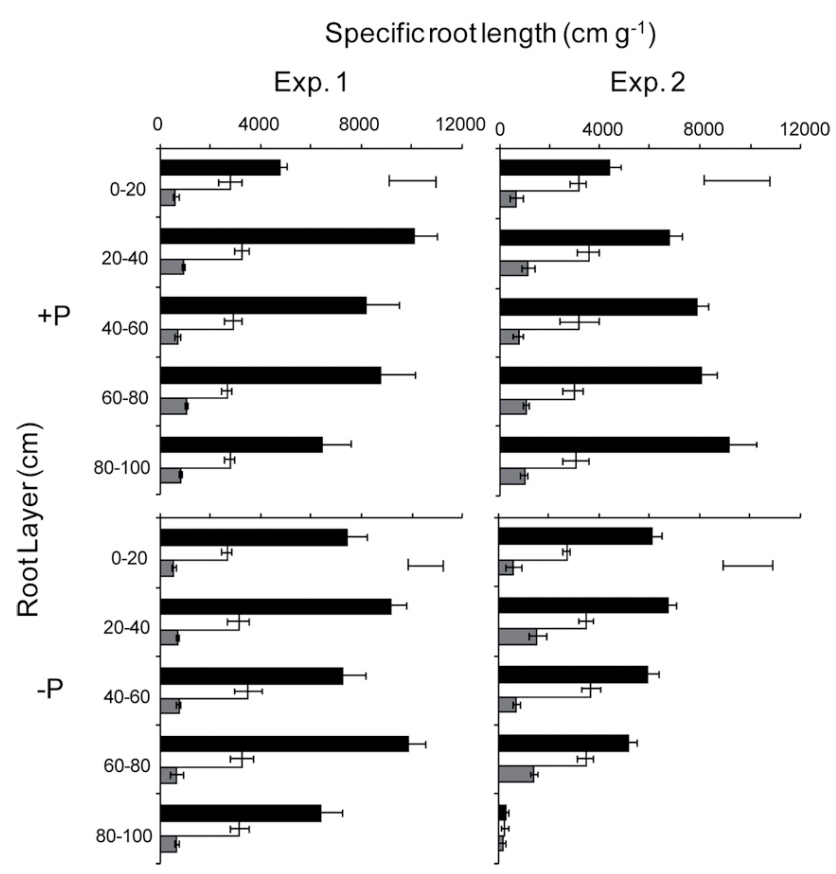

Figure 5. Specific root length of wheat (black bars), pea (white bars) and lupin (grey bars) at different soil layers in treatment P1 (upper panels) and P0 (lower panels) in Experiment 1 (right panels) and 2 (left panels). The horizontal bars which appear on the bars represent the standard error of the means., while the horizontal bars which appear alone represent Tukey test at $\mathrm{P}=0.05$.

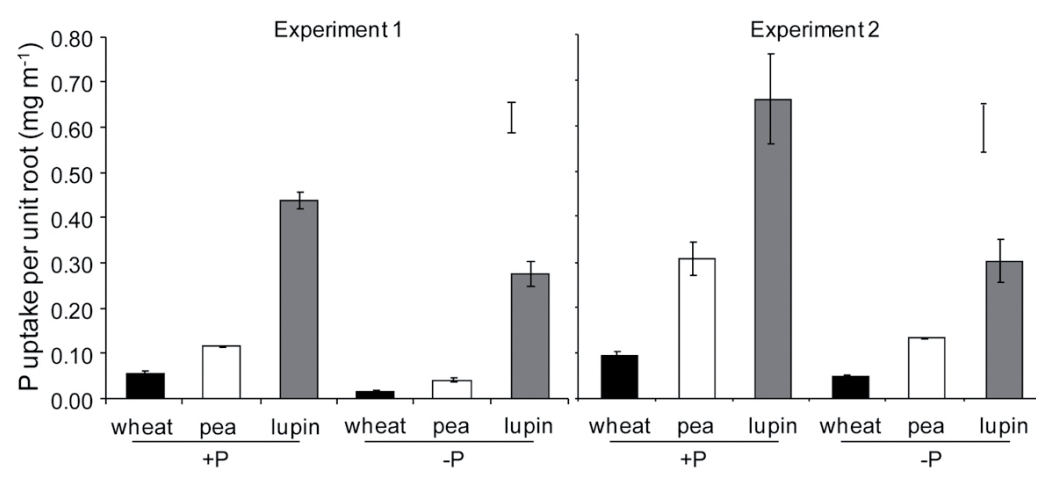

Figure 6. Phosphorus uptake per unit of root length of wheat (black bars), pea (white bars) and lupin (grey bars) $\mathrm{P} 1$ and P0 fertilization in Experiments 1 and 2. The vertical bars which appear on the bars represent the standard error of the mean, while the horizontal bars which appear alone represent Tukey test at $\mathrm{P}=0.05$. 


\section{Discussion}

Despite wheat having demonstrated lower internal nutrient requirements for growth $(\mathrm{N}$ or $\mathrm{P})$ relative to legumes (Ma et al., 2011; Sandaña and Pinochet, 2014), shoot biomass and yield responses of wheat to P supply have been shown, as in the present study, to be higher than grain legumes such as pea (Bolland et al., 1999; Li et al., 2011), lupin (Bolland et al., 1999) and bean (Phaseolus vulgaris L.) (Föhse et al., 1988). This means that wheat needs higher $P$ levels in soil (high external $\mathrm{P}$ requirement) than legumes to reach its potential growth. On this issue, Föhse et al. (1988) concluded that differences in external P requirements are caused by differences in the $\mathrm{P}$ uptake efficiency of the root system. This is consistent with previous studies focused on root traits related to $\mathrm{P}$ uptake efficiency and consequently the PUE of crops (Gahoonia and Nielsen, 2004).

The main variables of root systems involved in the P uptake efficiency of plants are the size of the root system, specific root length the ratio of root length to shoot weight, and the inflow per unit root length (Föhse et al., 1988; Jungk, 2002; Watt and Evans, 2003). In this study, wheat showed the highest total root length and specific root length, and as a result a higher soil exploratory capacity than legumes. Contrasting root properties between cereals and legumes has been previously reported, where temperate cereals, such as wheat and barley, were shown to have a greater root biomass, length and specific root length than legumes, including lupin, pea, chickpea and soybean (Gregory, 1994; Gregory and Eastham, 1996; Wang et al., 2010). However, although wheat had a larger root system than legumes, the former species was still more sensitive to $\mathrm{P}$ supply (in yield and $\mathrm{P}$ uptake) than the latter. In addition, pea also showed a higher root soil exploratory capacity than narrowleafed lupin. Such differences between legumes have also been observed in other legumes such as soybean and white lupin (Watt and Evans, 2003). This study is the first attempt to compare these three species in the same experiment, showing that wheat had a higher both root length and specific root length than both legumes.

Another important root trait related to the P uptake efficiency of crops is the root: shoot ratio, as this determines the number of roots that can feed a unit of shoot (Jungk, 2002). Species in the present study showed contrasting root: shoot ratios (wheat $>$ pea $>$ narrow-leafed lupin). Differences in root: shoot ratios among species and cultivars have been also reported (Föhse et al., 1988; Wang et al., 2010); thus, this trait has been used as a selection criterion in breeding for P-efficient cultivars (Römer and Schenk, 1998). The root: shoot ratio also varies with soil constraints, such as nutrient availability (Föhse et al., 1988; Glass, 2002) and soil compaction (Hoffmann and Jungk, 1995). As shown in the present study, the best-known root response to nutrient deficiency is the increase in the root: shoot ratio of plants. This adaptation allows for a more efficient allocation of available plant resources to soil exploration (Hoffmann and Jungk, 1995; Glass, 2002). These adaptation mechanisms improve uptake efficiency in plants when nutrients limit growth (Föhse et al., 1988). However, as in our study, nutrient deficiencies usually result in lower absolute root systems than in nutrient-sufficient conditions (Glass, 2002).

Crops with larger root systems, higher specific root length and higher root:shoot ratios are often considered as efficient for P uptake. However, the benefit of these traits is lost if $\mathrm{P}$ uptake per unit root is too small. In addition to root morphology traits, wheat, pea and narrow-leafed lupin also showed in the present study contrasting P uptake per unit of root length. This variable is an indicator of the net influx of $\mathrm{P}$ which is formally described by the kinetics equation of nutrient uptake derived from the Michaelis-Menten equation 
(Jungk, 2002; Gahoonia and Nielsen, 2004). The parameters of $\mathrm{P}$ uptake kinetics may vary depending on nutritional status and genotype (Jungk, 2002). As in the present study, consistent genotype differences in the $\mathrm{P}$ influx rate in seven species with contrasting root:shoot ratios were observed in a study by Föhse et al., 1998. These authors described the strategies which plants have developed for high uptake efficiency as differing among species. Some produce large root systems (such as wheat), while others have high uptake rates per unit of root length (pea and narrowleafed lupin). Our results also agree with the study by Araújo et al. (1998), who observed a compensatory mechanism of P uptake among common bean genotypes, where simple linear regressions indicated a significant negative relationship between the total root area and the $\mathrm{P}$ influx rate.

Rhizosphere activity allows nutrients to transform, mobilize and solubilize from a limited pool in the soil and enables the subsequent uptake of essential nutrients by plants to achieve crop genetic potential (Hinsinger, 2011). Higher $P$ uptake per unit length could be ascribed to legumes exuding greater amounts of phosphatases and carboxylates than wheat (Nuruzzaman et al., 2006). In addition, Watt and Evans (2003) showed in a comparative study that white lupin accumulated 4.8 times more $\mathrm{P}$ per unit of root length than soybean, while soybean had 3.4 times higher root length per plant dry weight than white lupin. It was suggested that the high $\mathrm{P}$ acquisition per root length showed by white lupin involved other mechanisms such as the exudation of $\mathrm{P}$ solubilizing compounds. On the other hand, crop differences in acquiring $\mathrm{P}$ could be attributed to the interaction with different plant growth promoting rhizobacteria, microorganisms interacting with plants in several ways (Vessey et al., 2003). For instance, phosphate-solubilizing bacteria (PSB) are rhizobacteria that convert insoluble phosphates into soluble forms through acidification, chelation, ex- change reactions and the production of organic acids (Viruel et al., 2014). There are no studies in wheat, pea and narrow-leafed lupin comparing the importance of root exudates and/or their interaction with PSB in order to acquire $\mathrm{P}$, which would allow us to explain possible differences among these species in relation to this topic. Therefore, further research into the exudation of P solubilizing compounds and PSB is required.

\section{Conclusion}

The present study comparatively evaluated the root properties of wheat, pea and narrow-leafed lupin under two $\mathrm{P}$ availabilities in terms of their ability to acquire $\mathrm{P}$ from the soil. The species assessed had different sensitivities to $\mathrm{P}$ deficiency regarding shoot biomass responses and $\mathrm{P}$ uptake. Wheat and narrow-leafed lupin showed the highest and the lowest sensitivities to P supply. The species also showed contrasting root properties related to $\mathrm{P}$ uptake efficiency. Wheat and narrow-leafed lupin showed the highest and the lowest cumulative root length. In addition, wheat, pea and narrow-leafed lupin showed the highest, intermediate and lowest root: shoot ratio and $\mathrm{P}$ uptake per unit of root length, respectively. The present study consistently showed differences between wheat, pea and narrow-leafed lupin regarding (i) their sensitivity to $\mathrm{P}$ deficiency and (ii) the strategies that these species have developed in order to acquire $\mathrm{P}$ from the soil. This information could be useful for crop management strategies aimed at improving $\mathrm{P}$ use efficiency.

\section{Acknowledgments}

The revision of English usage by Dr. Helen Lowry is highly appreciated. Patricio Sandaña held a postgraduate scholarship from CONICYT-2010. 


\section{References}

Araújo, A., Teixeira, M., de Almeida, D. 1998. Variability of traits associated with phosphorus efficiency in wild and cultivated genotypes of common bean. Plant Soil. 203, 173-182.

Balemi, T., Negisho, K. 2012. Management of soil phosphorus and plant adaptation mechanisms to phosphorus stress for sustainable crop production: a review. J. Soil Sci. Plant Nutr. 12, 547-561.

Bayuelo-Jiménez, J.S., Ochoa-Cadavid, I. 2014. Phosphorus acquisition and internal utilization efficiency among maize landraces from the central Mexican highlands. Field Crops Res. 156, 123-134.

Bolland, M., Siddique, K., Loss, S., Baker, M. 1999. Comparing responses of grain legumes, wheat and canola to applications of superphosphate. Nutr. Cycli. Agro. 53, 157-175.

Cordell, D., Drangert, J.-O., White, S. 2009. The story of phosphorus: Global food security and food for thought. Global Environ. Chan. 19, 292-305.

Föhse, D., Classen, N., Junk, A. 1988. Phosphorus efficiency of plants. I. External and internal $\mathrm{P}$ requirement and $\mathrm{P}$ uptake efficiency of different plant species. Plant Soil. 110, 101-109.

Gahoonia, T., Nielsen, N. 2004. Barley genotypes with long root hairs sustain high GY in low-P field. Plant Soil. 262, 55-62.

Giunta, F., Pruneddu, G., Motzo, R. 2009. Radiation interception and biomass and nitrógeno accumulation in different cereals and grain legume species. Field Crops Res. 110, 76-84.

Glass, A. 2002. Nutrient absorption by plant roots: regulation of uptake to match plant demand. In: Plant Roots The Hidden Half. Edited by Waisel, Y., Eshel, A. and Kafkafi, U. Marcel Dekker, Inc. New York. 571-586p.
Gregory, P. 1994. Resource capture by root networks. In: Resource Capture by Crops: Edited by Monteith, J. Scott, R and Unsworth Full-size image. Nottingham University Press, Loughborough, U.K. pp. $78-95$.

Gregory, P., Eastham, J. 1996. Growth of shoots and roots, and interception of radiation by wheat and lupin crops on a shallow, duplex soil in response to time of sowing. Aust. J. Agric. Res. 47, 427447.

Gregory, P.J., George, T.S. 2011. Feeding nine billion: the challenge to sustainable crop production. J. Exp. Bot. 62, 5233-5239.

Hinsinger, P., Brauman, A., Devau, N., Gérard, F., Jourdan, C., Laclau, J.P., Le Cadre, E., Jaillard, B., Plassard, C. 2011. Acquisition of phosphorus and other poorly mobile nutrients by roots. Where do plant nutrition models fail?. Plant Soil. 348, 29-61.

Hoffmann, C., Jungk, A. 1995. Growth and phosphorus supply of sugar beet as affected by soil compaction and water tension. Plant Soil. 176, 15-25.

Jungk, A. 2002. Dynamics of nutrient movement at the soil-root interface. In: Plant Roots The Hidden Half. Edited by Waisel, Y., Eshel, A., Kafkafi, U. Marcel Dekker, Inc. New York. 587-614p.

Li, S.X., Wang, Z.H., Stewart, B.A. 2011. Differences of some leguminous and nonleguminous crops in utilization of soil $\mathrm{P}$ and responses to phosphate fertilizers. Adv. Agron. 110, 125-249.

Liao, M., Palta, P., Fillery, I. 2006. Root characteristics of vigorous wheat improve early nitrogen uptake. Aust. J. Agric. Res. 57, 1097-1107.

Ma, Q., Rengel, Z., Siddique, K. 2011. Wheat and White lupin differ in root proliferation and phosphorus use efficiency under heterogeneus soil $\mathrm{P}$ supply. Crop Past. Sci. 62, 462-473. 
Ortiz-Monasterio, J., Manske, G., and van Ginkel, M. 2001. Nitrogen and phosphorus use efficiency. In: Application of Physiology in wheat Breeding. Reynolds, M., Ortiz-Monasterio, J. McNab, A. (Eds). CIMMYT, Mexico. pp. 200-207.

Römer, W., Schenk H. 1998. Influence of genotype on phosphate uptake and utilization efficiencies in spring barley. Eur. J. Agron. 8, 215-224.

Sandaña, P., Pinochet, D. 2014. Grain yield and phosphorus use efficiency of wheat and pea in a high yielding environment. J. Soil Sci. Plant Nutr. 14, 973-986.

Sandaña, P. 2016. Phosphorus uptake and utilization efficiency in response to potato genotype and phosphorus availability. Europ. J. Agronomy. 76, 95-106.

Tennant, D., 1975. A test of a modified line intersect method of estimating root length. J. Ecol. 63, 995-1001.
Valle, S.R., Carrasco, J., Pinochet, D., Soto, P., Donald, R.M. 2015. Spatial distribution assessment of extractable $\mathrm{Al},(\mathrm{NaF}) \mathrm{pH}$ and phosphate retention as tests to differentiate among volcanic soils. Catena $127,17-25$.

Vessey, K. 2003. Plant growth promoting rhizobateria as biofertilizers. Plant Soil. 255, 571-586.

Viruel, E.,L.E. Erazzú, L. Martínez Calsina, M.A. Ferrero, M.E. Lucca, F. Siñeriz. 2014. Inoculation of maize with phosphate solubilizing bacteria: effect on plant growth and yield. J. Soil Sci. Plant Nutr. 14, 819-831.

Wang, X., Tang, C., Guppy, C.N., Sale, P. 2010. Cotton, wheat and white lupin differ in phosphorus acquisition from sparingly soluble sources. Environ. Exp. Bot. 69, 267-272.

Watt, M., Evans, J., 2003. Phosphorus acquisition from soil by white lupin (Lupinus albus L.) and soybean (Glycine $\max$ L.), species with contrasting root development. Plant Soil. 248, 271-283. 